\title{
Education
}

INLIFESTYLE MEDICINE

\section{The American Board of Lifestyle Medicine}

(f ' $m$ a serious and conscientious lifestyle medicine practitioner, and I don't want to be confused with the voodoo merchants and snake oil salesmen out there. We need lifestyle medicine certification!" That sentiment, often expressed and passionately put forward, has been part of the regular feedback that the American College of Lifestyle Medicine (ACLM) has received almost from its inception in 2004. "How can we differentiate the evidence-based lifestyle medicine practitioners from the ones who sell $\$ 4000$ amulets or prescribe lemon detox diets? Please do something about this!"

Over the past 10 years, the lifestyle medicine movement has gathered momentum, with ACLM memberships steadily rising and attendance at the annual summit increasing rapidly. However, nobody had properly figured out how to make lifestyle medicine financially viable for physicians and other health professionals, and early adaptors struggled to make ends meet, practicing their craft. It became more and more evident that without a regulatory framework that included practitioner certification, health insurance companies and self-insured employers would continue to be reluctant to embrace lifestyle medicine as the first port of call in the prevention, arrest and reversal of chronic disease, and therefore be willing to pay for addressing the root causes in the same manner as they were willing to pay for addressing the symptoms (through medication).

In mid-2015, some of the stalwarts of the lifestyle medicine family therefore decided that the time had come to make the implementation of a certification framework a priority. It was decided that lifestyle medicine should remain in the house of medicine, despite a strong push from some quarters to expand the boundaries and incorporate issues like global warming or veganism as an animal rights ideology in the cause. certification for $\mathrm{PhD}$ and masters level health professionals.

To that end, the American Board of Lifestyle Medicine (ABLM) was formed in early 2016. A generous grant from the Ardmore Institute of Health allowed a consultant to be engaged to create the certification framework, which was presented and approved by the board at the end of June. This framework included the establishment of ABLM as a not-for-profit company (501c6), the appointment of an Executive Director to

\section{Over the past 10 years, the lifestyle medicine movement has gathered} momentum, ...

Although these are worthy pursuits for many in the lifestyle medicine arena, it was determined that with a desire to eventually be accepted as a subspecialty by the American Board of Medical Specialties, the focus should remain on the evidence-based "medicine" part. It was further determined that in order to achieve subspecialty status, established pathways would have to be followed, rather than going it alone and creating something that the ABMS would dismiss out of hand. Those established pathways would require a separation of certification for MDs and DOs from implement the framework, the creation of an item writing team and item bank, the determination of certification prerequisites and acceptable Continuing Medical Education (CME) sources, the implementation of a website with online certification registration (www.ablm.co) as well as the creation of the inaugural certification examination on Thursday, October 26, 2017, as part of the ACLM summit in Tucson, Arizona.

It was determined that 30 hours of online CME, 10 hours of in-person CME, and a case study would be required as prerequisites for the certification, with

DOI: 10.1177/1559827616686527. From the American Board of Lifestyle Medicine, Riverside, California (SH, WD), Duke \& Co Pty Ltd, Keilor Lodge, Victoria, Australia (SH), and Lifestyle Medicine Solutions, Riverside, California (WD). Address correspondence to: Stephan Herzog, Executive Director, American Board of Lifestyle Medicine, 4368 Central Avenue, Riverside, CA 92506; e-mail: stephan.herzog@ablm.co.

For reprints and permissions queries, please visit SAGE's Web site at http://www.sagepub.com/journalsPermissions.nav. 
the CMEs not older than 36 months from the date of the examination. This to ensure that knowledge was current and that diplomates would be evidencebased practitioners of lifestyle medicine rather than theoreticians. The 30 hours of online CME could come from the ACLM/ ACPMs Lifestyle Medicine Core Competencies Course (LMCC), the Institute of Lifestyle Medicine (ILM) at Harvard University courses or the Cornell University plant-based nutrition course. Attendance at the ACLM, the ILM, the Food as Medicine or the Plantrician Project summits would give you the required 10 hours of in-person CMEs (for more information, please visit www. ablm.co).

The lifestyle medicine certification core competencies are summarized as follows:

1. Introduction to lifestyle medicine

2. Fundamentals of health behavior change
3. Key clinical processes in lifestyle medicine

4. The role of physician health

5. Nutrition science, assessment and prescription

6. Physical activity science and prescription

7. Emotional and mental well-being, assessment and interventions

8. Sleep health science and interventions

9. Fundamentals of tobacco cessation and managing risky alcohol use

10. Weight management

One of the unique aspects of the ABLM is the inclusion of the Executive Directors of the international lifestyle medicine organizations at the continental levels as non-voting ex-officio members. From the very start it has been the desire of the lifestyle medicine movement to be a global force, and the existence of the Lifestyle Medicine Global Alliance (lifestylemedicineglobal. org), brought to life by Susan Benigas (Executive Director of ACLM) and Dr Margarete Ezinwa is testament to that. These international lifestyle medicine organizations not only contribute to the item writing, they have also committed to using the ABLM examination in private labeled form, and apply the same prerequisites for certification, so that for the first time in history a medical discipline will have the same framework and examination all around the globe. While the examination, scoring, and passing rates will be the same on all continents, the

certifications themselves will be issued by the relevant country or continental lifestyle medicine boards/colleges/ societies, together with the seal of approval by the International Board of Lifestyle Medicine (IBLM), which is an offshoot of the ABLM.

The following table illustrates the roles and responsibilities of the various entities:

\begin{tabular}{|l|l|}
\hline American Board of Lifestyle Medicine & Certifies MDs and DOs practicing in the United States \\
\hline American College of Lifestyle Medicine & Certifies PhD and masters level health professionals practicing in the United States \\
\hline International Board of Lifestyle Medicine & $\begin{array}{l}\text { Co-certifies MDs, DOs, PhD, and masters level health professionals both in the United } \\
\text { States and internationally }\end{array}$ \\
\hline Continental Lifestyle Medicine Associations & Certify MDs, DOs, PhD, and masters level health professionals in their jurisdictions \\
\hline
\end{tabular}

It is very exciting to see this international collaboration come to fruition.

"So, what will I get if I get lifestyle medicine certified? Why should I bother?" That is a frequently asked and absolutely legitimate question by physicians and other health professionals. To put it into the words of one of the ABLM board members:
Certification tells the world that you have mastered the discipline, that you are legitimate, and that you know how to treat the underlying cause of chronic disease. It separates you from the crowd and it attests to your attainment of rigorous high professional standards! It also prepares you for insurance reimbursements, which are likely to come only to certified individuals!

\section{Declaration of Conflicting Interests}

The author(s) declared no potential conflicts of interest with respect to the research, authorship, and/or publication of this article. AJLM 